\title{
Research on Special Measures of Safe Abandonment of a Ship in Polar Waters
}

\author{
Wang Deling ${ }^{*}$, Geng Hejun, Fan Fuquan, Tao Qingfeng \\ Merchant Marine College, Shanghai Maritime University, Shanghai, China \\ Email address: \\ dlwang@shmtu.edu.cn (Wang Deling), genghj@shmtu.edu.cn (Geng Hejun), fanfq@shmtu.edu.cn (Fan Fuquan), \\ qftao@shmtu.edu.cn (Tao Qingfeng) \\ *Corresponding author
}

\section{To cite this article:}

Wang Deling, Geng Hejun, Fan Fuquan, Tao Qingfeng. Research on Special Measures of Safe Abandonment of a Ship in Polar Waters. Journal of Water Resources and Ocean Science. Vol. 8, No. 4, 2019, pp. 44-49. doi: 10.11648/j.wros.20190804.11

Received: September 10, 2019; Accepted: October 4, 2019; Published: October 15, 2019

\begin{abstract}
Ice melting in polar waters caused by global warming has been making it practicable for merchant ships to sail in polar area. Sailing distances from Far-east to West of Europe and East of North America are shortened by around 30\% by selecting polar routes, therefore, polar routes are considered as the golden routes. However, polar water has its unique risks for ships sailing in the areas. Those unique risks may cause adverse impacts to the survival of seafarers in case of emergencies. To ensure the safe abandonment of a ship in polar waters, this paper analyzes and summarizes the potential risks associated with polar shipping with respect to safe escape, evacuation and survival for seafarers in case of emergencies. Based on the analysis of unique potential hazards and inquiry with experts and seafarers who have experiences in polar ship operation and management, this paper provides practical measures to safeguard crew's escape, evacuation and survival in extreme polar circumstances when abandoning a ship. The requirements as to Life Saving Appliances and Arrangements in Polar Code are also interpreted in this paper, and those practical measures provided will help the ship owners, ship operators, and ship masters and seafarers to better understand and comply with the requirements of the Polar Code.
\end{abstract}

Keywords: Polar Waters, Unique Circumstances, Safe Abandonment of a Ship, Polar Code

\section{Introduction}

With the trend of global warming up caused by Green House Effect, ice in polar water is melting dramatically, making it practicable for merchant ships to sail in polar area. Routes from Far East to West Europe and to East of North America through Arctic waters are the shortest of all the existing routes. Therefore, polar routes are considered as the golden routes. Polar shipping will undoubtedly grow in volume and diversify in nature over the coming years. Driven by an ever increasing global demand for commodities like energy and mining products, ship traffic is likely to increase dramatically in the near future -- a trend that will increase the pressure on this relatively pristine area.

Ships operating in the remote polar waters will face various unique risks including poor weather condition, extremely low air temperature, darkness, ice accretion, difficulties in search and rescue or environmental clean-up operations, etc. Poor weather conditions can compound the relative lack of good charts, communication systems and navigational aids. Search and rescue or environmental clean-up operations can be extremely difficult and, as a result, potentially very costly. The cold temperatures and harsh weather systems can cause malfunctions of ship's machinery and equipment. Polar ice fields can impose additional loads on the ships' hull and propulsion.

To ensure the safety of shipping in polar waters, IMO has adopted the International Code for Ships Operating in Polar Waters (The Polar Code hereafter) and related amendments to make it mandatory under both SOLAS and MARPOL convention. The polar code entered into force on 1 January 2017. Due to the exceptional circumstances in polar waters, it is extremely hard for seafarers to survive in case of emergency and following ship abandonment. The polar code Chapter 8Life Saving Appliances and Arrangements, regulates the basic requirements, provides for safe escape, evacuation and survival. However, those regulations are only the basic requirements. Based on the analysis of unique potential hazards and inquiry with experienced seafarers sailing in polar waters, this paper 
this paper analyzes and provides practical measures to safeguard crew's escape, evacuation and survival in extreme polar circumstances in case of abandoning a ship.

\section{Analysis of Hazards in Polar Shipping with Respect to Safe Escape, Evacuation and Survival}

\subsection{Potential Hazards Associated with Polar Shipping}

IMO Sub-committee on Ship Design and Equipment
(DE 54/WP.3) presented on its 54th session, a hazard matrix identified on development of a Mandatory Polar Code. This matrix identified various hazards and their consequences in polar shipping. By referring to the matrix, a table of "Identified various hazards and their consequences in polar waters" is produced in this paper. These hazards uniquely endanger the seafarers in polar waters. To ensure the safe escape, evacuation and survival, those unique risks shall be fully taken into consideration. See table 1 below "Identified various hazards and their consequences in polar waters".

Table 1. Identified various hazards and their consequences in polar waters.

\begin{tabular}{|c|c|c|}
\hline Hazards & Consequences of the hazards & $\begin{array}{l}\text { Affecting the seafarers' safe } \\
\text { abandonment of a ship? }\end{array}$ \\
\hline \multirow{11}{*}{ Low air temperature } & Loss of performance of material, exposed to low temperature & Yes, survival boats \\
\hline & Malfunction of machinery & Yes, boat engines \\
\hline & Thicker viscosity fluid/cargo and machinery & Yes, boat engine fuels \\
\hline & Effect of cold cargo to hull materials & No \\
\hline & Loss of functionality of operating and emergency equipment & Yes, emergency escaping equipment \\
\hline & Reduced survival time/hypothermia & Yes, coldness and less survival time \\
\hline & Reduced human performance, physical and cognitive functions & Yes, human performance \\
\hline & Ice on deck and superstructure & Yes, escape route blocked \\
\hline & Freezing of ballast & No \\
\hline & Limitation of SAR capabilities & Yes, SAR operations \\
\hline & Reduced maneuverability & No \\
\hline \multirow[b]{2}{*}{ Low water temperature } & Reduced survival time & Yes, coldness and less survival time \\
\hline & Malfunction of fluid systems & Yes, boat engine fuels \\
\hline \multirow{7}{*}{$\begin{array}{l}\text { Extreme and rapidly } \\
\text { changing weather condition }\end{array}$} & Difficult to prepare for or avoid dangerous weather conditions & Yes \\
\hline & Propulsion and/or manoeuvring difficulties & No \\
\hline & Reduced survivability /hypothermia & Yes, coldness and less survival time \\
\hline & Increased risk of human error & Yes \\
\hline & Injuries due to ice flow/falling on deck & Yes \\
\hline & Capsize and operational threats to smaller vessels, auxiliary boats and tenders & Yes, survival boat \\
\hline & Limitation of SAR capabilities & Yes, SAR operations \\
\hline \multirow{7}{*}{$\begin{array}{l}\text { Presence and variability of } \\
\text { sea ice }\end{array}$} & Structure failure due to impact with ice or pressured ice & Yes, survival boats \\
\hline & Hull penetration and structure deformation & Yes, survival boats \\
\hline & Disturbance in navigation due to icebergs & No \\
\hline & $\begin{array}{l}\text { Propulsion and/or maneuvering difficulties/failure } \\
\text { Different stability characteristics in ice }\end{array}$ & Yes, survival boats \\
\hline & Damage to anti-collision systems & No \\
\hline & Reduced propulsion system capacities & No \\
\hline & Inability to operate evacuation systems due to surrounding ice & Yes \\
\hline \multirow{9}{*}{$\begin{array}{l}\text { Ice on deck and } \\
\text { superstructures }\end{array}$} & Malfunction of navigational aids & No \\
\hline & Injuries to personnel & Yes \\
\hline & Blocking of air intakes, air ventilation and pressure release valves & Yes, survival boats \\
\hline & Exposure of personnel to de-ice (chemicals) & Yes \\
\hline & Possibility of damage to equipment during de-icing & No \\
\hline & Malfunctioning of deck machinery & No \\
\hline & Overload due to ice & Yes, survival boats \\
\hline & Restrictions of human activities & Yes \\
\hline & Hypothermia & Yes \\
\hline \multirow{4}{*}{ Reduced navigational aids } & Grounding, stranding, trapped in ice & No \\
\hline & Impact with ice or other structures & No \\
\hline & Lack of signals/disturbance DGPS & Yes \\
\hline & Unstable gyro & No \\
\hline \multirow{4}{*}{$\begin{array}{l}\text { Varying availability of } \\
\text { charts/hydro-graphical } \\
\text { information } \\
\text { Varying availability }\end{array}$} & Grounding, stranding & No \\
\hline & Voyage planning & No \\
\hline & Anchoring & No \\
\hline & Voyage planning & No \\
\hline
\end{tabular}




\begin{tabular}{|c|c|c|}
\hline Hazards & Consequences of the hazards & $\begin{array}{l}\text { Affecting the seafarers' safe } \\
\text { abandonment of a ship? }\end{array}$ \\
\hline meteorological & Difficult to prepare for or avoid dangerous weather conditions/ situations & Yes \\
\hline information/Ice data & Insufficient clothing and supplies (optimistic planning) & Yes, hypothermia \\
\hline \multirow[b]{3}{*}{ Variable infrastructure } & Insufficient actions to incidents and accidents & Yes \\
\hline & Insufficient spill preparedness & No \\
\hline & $\begin{array}{l}\text { Limited compliance and enforcement (local infrastructure, waste reception } \\
\text { facilitation) }\end{array}$ & No \\
\hline \multirow{3}{*}{$\begin{array}{l}\text { Interference with long-range } \\
\text { electronic communications }\end{array}$} & Loss of possibility to send distress messages/contact SAR & Yes \\
\hline & No weather/ice forecast & Yes \\
\hline & Loss of communication possibilities & Yes \\
\hline $\begin{array}{l}\text { Variable communication } \\
\text { capabilities }\end{array}$ & Communication difficulties & Yes \\
\hline \multirow{2}{*}{$\begin{array}{l}\text { Limited search and rescue } \\
\text { capabilities }\end{array}$} & Insufficient response to incidents and accidents & Yes \\
\hline & Lack of medical support & Yes \\
\hline \multirow{4}{*}{$\begin{array}{l}\text { Limited availability of oil } \\
\text { spill preparedness }\end{array}$} & Insufficient response to spills & No \\
\hline & Damage to ecological systems & No \\
\hline & Damage to flora and fauna & No \\
\hline & Potential for incidences to escalate & No \\
\hline
\end{tabular}

Note: The Table 1 above gives 13 types of hazard faced by ships when sailing in polar waters, and the possible consequences for each hazards are listed in column 2. Not all the hazards in the table pose a danger to the crew abandoning the ship in an emergency. Therefore, in column 3 whether the danger and consequences affecting the abandonment of the ship is given, If yes, a short explanation is followed to indicate the effects.

\subsection{Potential Hazards with Respect to Safe Escape, Evacuation and Survival}

Based on the specific hazards and consequences above, this paper analyzed and selected all potential hazards associated closely with seafarers' safe escape, evacuation and survival in case of emergency when sailing in polar waters, and grouped them into five categorizes as follows.

1) Low temperature affecting the stowage and deployment of life-saving appliances

For ships sailing in polar waters, coldness is one of the greatest dangers. The temperature of polar region can reach to below $-50^{\circ} \mathrm{C}$. Low temperature increase the viscosity of oil products, decrease the self-priming capacity of oil pump and the pressure of hydraulic system, thus causing the hydraulic system fail. The low temperature effect on all liquids in the lifeboats should be taken into consideration when installed, e.g. special fuel, lubrication oil cooling water for the engine.

2) Ice built-up hampering life-saving appliances

It is possible that sub-zero temperatures would cause ice accretion. The life-saving appliances may malfunction when covered by ice. All the life-saving appliances should be designed or protected against ice accretion so that it is operable in case of abandoning the ship.

3) Launching of survival craft on ice-covered waters

The standard free-fall lifeboat in accordance with IMO provisions includes arrangements that allow only a lowering aft of the ship. It is impossible for a vessel to launch free-fall life boat onto ice. If a lifeboat should be lowered onto ice, the slope of the bottom of the boat hull must be considered and equipment for limiting the heel must be provided.

4) Threats to survival in polar waters after abandonment

Survivors in lifeboats and life rafts, after a casualty in polar waters, may be expected to spend longer time on board such survival craft than is considered normal for survivors in most other parts of the world. Additionally, they will be exposed to climate conditions that are much more demanding and which require specific mitigating measures such as proper clothing, immersion suits or heating appliances in order to prevent hypothermia.

5) Limited search and rescue capabilities

In the remote polar waters, due to the sparse population along the polar coast and less vessel traffic, few rescue forces are stationed. Once a ship disaster take place, even if the distress signal could be sent immediately, it may take several hours or even a few days for the rescue force to arrive. Seafarers in distress will face the threats of drifting at sea and waiting for rescue resources for much longer time than that in normal shipping waters.

In addition to those identified hazards above, there may be some other hazards that are not identified for lack of resources and experiences in polar shipping. Further work should be continued and further resources related to polar shipping should be gathered.

\section{Requirements of Polar Code Chapter 8 - Life Saving Appliances and Arrangements}

The influence of polar environment on life saving and communication equipment is mainly manifested in four aspects: low temperature, ice and snow accumulation, abandonment of ships in ice area and lack of rescue resources. Low temperature may cause some life-saving and communication equipment to fail, such as the lifeboat releasing device, machinery, the batteries, etc.; Ice and snow accumulation snow may cause the escape route and access to 
muster station blocked; In case of abandoning a ship in the ice area, it may be difficult to release the survival rafts, and even the rafts can be launched, it may quite difficult to operate them in ice; Lack of rescue resources may lead to longer awaiting time for the survivors.

In view of the adverse effects of polar environment on marine survival, to ensure the life safety of seafarers during and after abandonment, the Polar Code provides mandatory provisions on the life-saving appliances and arrangement of polar vessels in Chapter 8, Part I-A. In brief, those requirements/regulations are divided into three sections: Escape, evacuation and survival. To make it more clear, a table interpreting the requirements is created in this paper. See Table 2 below.

Table 2. Requirements of Life Saving Appliances and Arrangements in Polar Code.

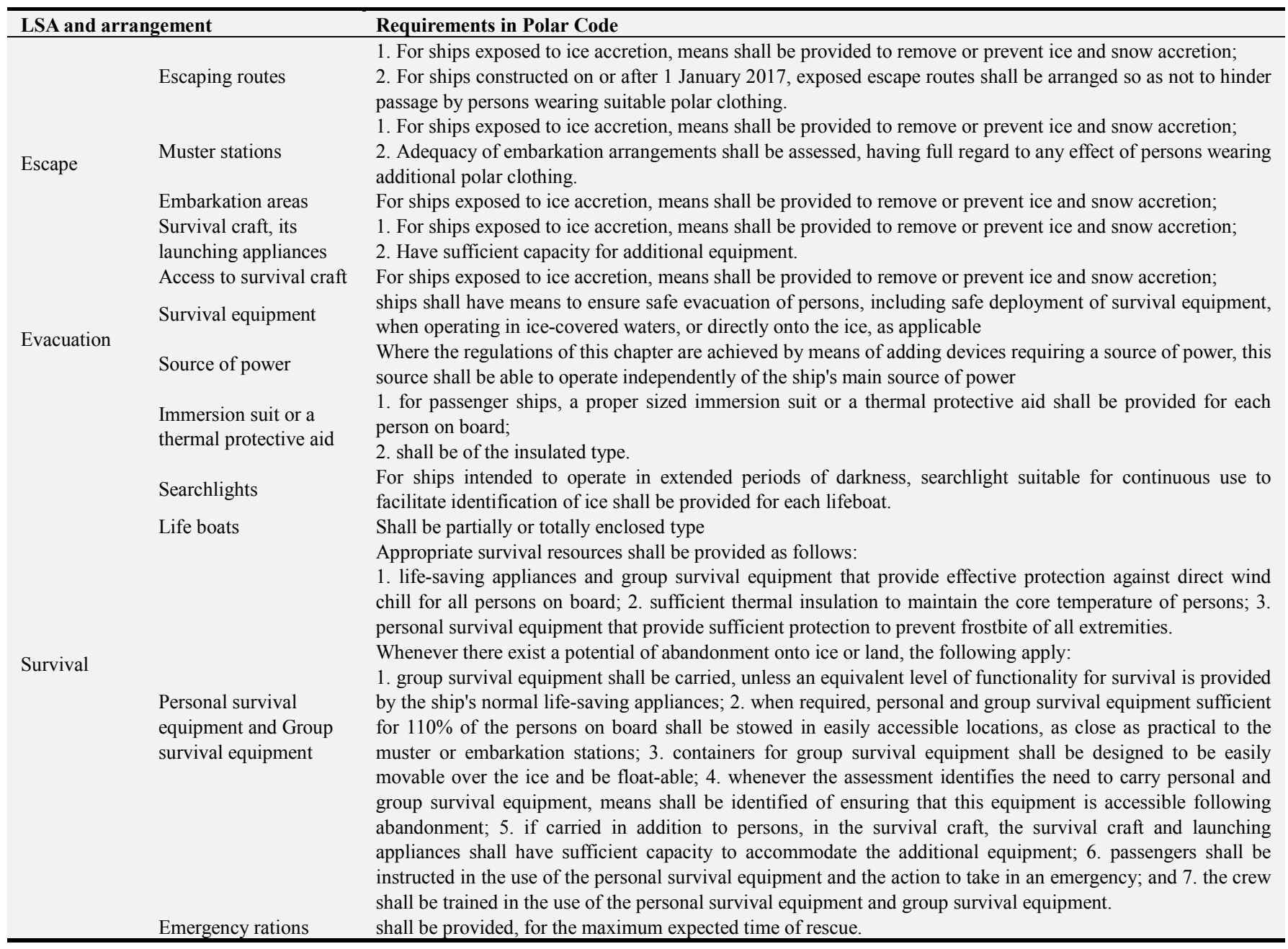

\section{Recommended Measures Taken by Polar Ships}

The Polar Code is a mandatory code enforced by SOLAS and MARPOL convention to ensure the safe operation of ships in polar waters. All the ships sailing in polar region shall comply with the requirements. However, those regulations provide only the basic requirements, and those clauses usually do not give specific measures, and the specific measures are usually realized by the ship itself, as long as it meets the mandatory requirements.

By inquiry to and/or questionnaires feedback from various experienced mariners and experts engaged in polar shipping, and based on the potential risks along with polar shipping, preventive measures are extracted and recommended to be taken to ensure the safe operation in polar shipping.

1) In addition to the equipment stated in the Code, extra protective clothing is recommended to carry on board such as winter hats, winter gloves, winter socks, face and neck protections, and make them ready for use in case of cold weather encountered.

Sufficient de-icing tools should be provided such as long handle axes, glue bars, round strong wood, spanners, pneumatic guns, and machinery tools to remove ice accretion near the survival rafts and escape routes.

2) When evacuating in polar waters, crew members may need to wear bulky thermal clothes, and ordinary escape routes may not allow them to pass through quickly and smoothly. Therefore, Escaping routes should be designed as wide as possible to ensure the safe passage by persons wearing suitable polar clothing 
and should not be blocked by any obstruction;

3) For exposed liquids e.g. fuel oil and cooling water for boat engines, if possible, arrange the piping systems in covered spaces with heating protections. Otherwise, protect them with insulting lagging to prevent from frozen or other protective measures;

4) When considering resources to be included with the personal and group survival equipment, reference can be made to Polar Code Part I-B Chapter 9 - Additional guidance to $\mathrm{Ch} 8$ (Life-Saving Appliances and Arrangements). See table 3 "Suggested Equipment for group survival equipment". Shelter e.g. tents or storm shelters or equivalent, thermal protective aids or similar, sleeping bags or foam sleeping mats or similar, and stove and fuel as listed in table 3 are considered as essential equipment, and are recommended to be provided on board, as they can provide effective protections to survivors in extremely code atmosphere.

Table 3. Suggested Equipment for group survival equipment.

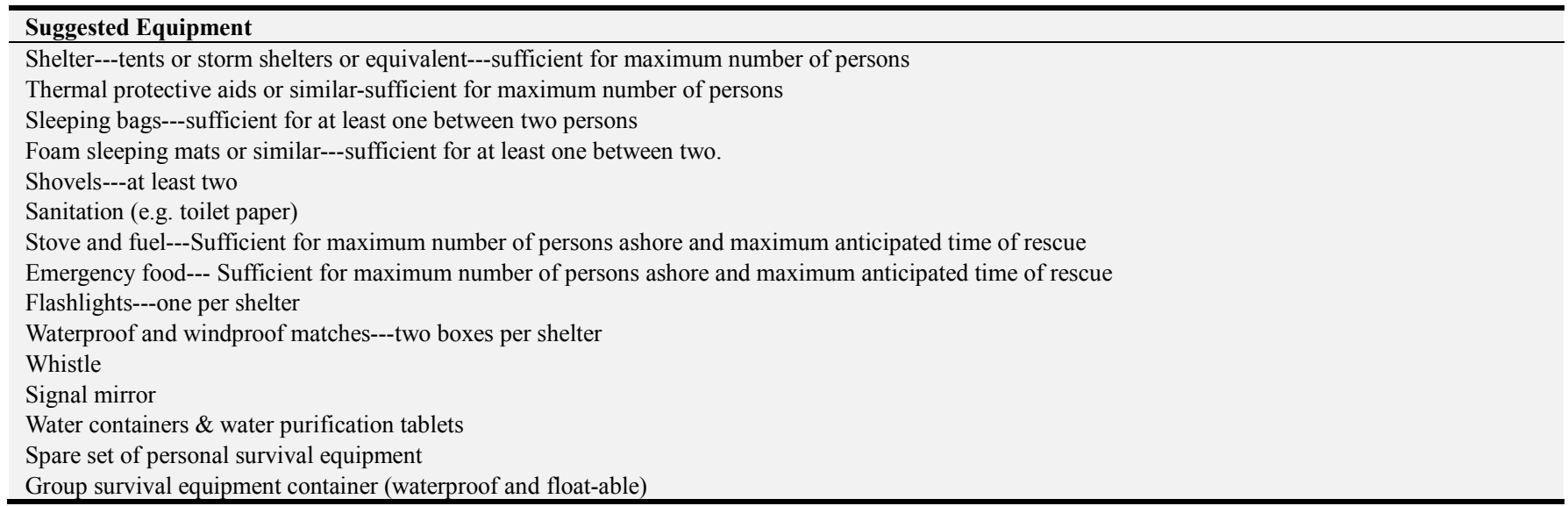

5) Sufficient emergency food ration and fresh water shall be provided more than that of ships sailing in ordinary waters for the expected longer waiting periods, e.g. double the amount.

6) For ships intended to operate in extended periods of darkness, each lifeboat needs to be provided with additional searchlights suitable for continuous use to facilitate identification of ice.

7) SOLAS requires that ships built after 1 July 1986 shall be equipped with partially or fully enclosed lifeboats. In general, it is expected that such lifeboats provide a good protection against the harsh environmental conditions. Therefore, only ships with partially or fully enclosed lifeboats should operate in polar waters. This requirement has been included in Guidelines for Ships Operating in Polar Waters (resolution A. 1024 (26)). However, due to the harsh environment, both partially enclosed and enclosed lifeboats will operate with doors closed, thus with very low ventilation. It may cause lack of oxygen and concentration of $\mathrm{CO}_{2}$ in the life boats. In view of this, bottles containing sufficient oxygen are recommended to be included in the group survival equipment for emergency use in case that the ventilation is not practicable due to extreme coldness.

8) For individual ships operating in ice-covered waters, LSA should be provided in such a way that e.g. lowering of a lifeboat onto the ice is possible. The standard free-fall lifeboat in accordance with IMO provisions includes arrangements that allow only a lowering aft of the ship. Another means of launching may need to be required since the area aft of the ship will be closed again by drifting ice. Alternatively to the installation of a davit system, the shape of lifeboat could be optimized and the hull strengthened so that the lifeboat can withstand the ice interaction. If lifeboats should be lowered onto the ice, the slope of the bottom of the lifeboat hull must be considered and equipment for limiting the heel must be provided. To solve these problems proposed by Germany to DE Subcommittee on its 56th session, a complete modification shall be done to lifeboats, e.g. bottom of lifeboat hull shall be modified to be flat for polar ships.

9) Any other measures that are deemed helpful in polar operation should be actively promoted.

\section{Conclusions}

The anticipated growth in polar traffic for a variety of shipping sectors brings a number of challenges to mariners and ship operators, of which safety is of vital importance, especially when a ship is in disaster followed by its abandonment.

The unique characteristics in polar water e.g. remoteness, high latitude, hash weather condition, darkness, and existence of ice, impose great dangers to safe polar shipping. It will be even much more dangerous in polar waters than that in other waters for ship's crew to escape and survive in case of emergency. To enhance the safe abandonment of a ship in polar waters, this paper identifies a variety of potential hazards, and provided targeted solutions for the hazards faced by mariners. However, there may be some hazards that are not identified due to lack of resources and experiences in polar shipping, and further work should be continued and further resources related to polar shipping should be gathered 
so as to make continuous amendment to polar and related conventions and codes, thus enhancing constant improvement in safe shipping in polar waters.

These measure serves only as a guidance for operators. Alternative measures can be introduced and encouraged, as long as the measures implemented can meet the requirements of the Polar Code and helps to cope with the expected dangers in polar shipping.

\section{References}

[1] IMO. the International Code for Ships Operating in Polar Waters $[\mathrm{M}]$. London, International Maritime Organization, 2016.

[2] Fedi, Faury, Gritsenko. The impact of the Polar Code on risk mitigation in Arctic waters: a "toolbox" for underwriters? [J]. Maritime Policy \& Management, 2018, 45 (4).

[3] IMO. IMO Resolution A. 1024 (26), GUIDELINES FOR SHIPS OPERATING IN POLAR WATERS [S].

[4] LI Weifang, HUANG Yan. International code for ships operating in polar waters: challenges to polar shipping safety rules in China [J]. Advances in Polar Science, 2016, 27 (03): 146-153.

[5] K E Solberg. Implications caused by SARex on the implementation of the IMO polar code on survival at sea [J]. IOP Conference Series: Materials Science and Engineering, 2017, 276 (1).

[6] IMO. SOLAS, consolidated edition 2014: consolidated text of the International Convention for the Safety of Life at Sea, 1974, and its Protocol of 1988: articles, annexes and certificates [M]. London, International Maritime Organization, 2014.
[7] IMO. MARPOL: consolidated edition 2017 [M]. London, International Maritime Organization, 2017.

[8] IMO. DE sub-committee, 54th session, Report of the Working Group on Development of a Mandatory Polar Code, 27 October $2010 \quad$ [EB/OL]. https://docs.imo.org/Category.aspx?cid=3

[9] HAN Jialin. Research on governance of HFO use and carriage on ships in accordance with the Polar Code [J]. Advances in Polar Science, 2018, 29 (04): 283-290.

[10] Sanderson TJ. Ice Mechanics-risks to offshore Structures. London: Graham \& Trotman, 1988.

[11] Risca K. Design of icebreaker ships. Cold Regions Science and Marine Technology, Encyclopedia of Life Support Systems (EOLSS), 2012.

[12] Samrat Ghosh, Christopher Rubly. The emergence of Arctic shipping: issues, threats, costs, and risk-mitigating strategies of the Polar Code [J]. Australian Journal of Maritime \& Ocean Affairs, 2015, 7 (3).

[13] White, Jonathan. The Polar Code-Bringing Order to Polar Shipping [J]. Sea Technology, 2015, 56 (4).

[14] Gold, Edgar. Shipping in Arctic Waters: A Comparison of the Northeast, Northwest and Trans Polar Passages [J]. Journal of Maritime Law and Commerce, 2014, 45 (2).

[15] Jabour, Julia. Progress towards the mandatory code for polar shipping $[\mathrm{J}]$. Australian Journal of Maritime and Ocean Affairs, 2014, 6 (1).

[16] Anderson, H Edwin. Polar Shipping, The Forthcoming Polar Code and Implications for the Polar Environments [J]. Journal of Maritime Law and Commerce, 2012, 43 (1).

[17] Pelletier, Sébastien, Lasserre, Frédéric. Arctic Shipping: Future Polar Express Seaways? Shipowners' Opinion [J]. Journal of Maritime Law and Commerce, 2012, 43 (4). 